\title{
Gamma Knife Treatment for Patients with Acoustic Neuroma: Bezmialem Vakif University Gamma Knife Unit Preliminary Results
}

Mustafa Aziz HATiBOĞLU1', Mahmut Hudai ÖZGÖR², Enes DiK², Hakan SEYTTHANOĞLU1', Saffet TÜZGEN

${ }^{1}$ Department of Neurosurgery, Bezmialem Vakıf University, İstanbul, Turkey

${ }^{2}$ Bezmialem Vakıf University School of Medicine, İstanbul, Turkey

\section{ABSTRACT}

Objective: Gamma Knife is a stereotactic radiosurgery technique that focuses radiation to a specific target in the brain using 192 or 201 different Co60 sources. Because Gamma Knife is effective and safe treatment, this technique is widely used for acoustic neuroma treatment. In this study, patients who treated with Gamma Knife for Acoustic neuroma were reviewed and effectiveness and its side effects were assessed.

Methods: Patients treated with Gamma Knife radiosurgery for acoustic neuroma between August 2014 - May 2015 were reviewed retrospectively. Magnetic resonance (MR) of brain before and after the Gamma Knife treatment for every 3 months period were assessed. Also, during that period clinical follow up was reviewed.

Results: During the study period, 18 patients (11 male and 7 female) were treated. Median age was 56 years (38-72). Lesion is on the left side in 14 patients (78\%), there is intracanalicular extension in $15(83 \%)$ and brainstem compression in four (22\%) patients. The median tumor volume before Gamma Knife was $1.94 \mathrm{~cm} 3(0.25-14 \mathrm{~cm} 3)$. The median treatment dose was $12.5 \mathrm{~Gy}(12-13 \mathrm{~Gy})$. Median follow up time was 4 months (1-8 months). Of these 18 lesions, size of the lesions decreased in three, increased in one and remained stable in 14 patients. Only one patient (\%6) developed hemiparesthesia, which resolved after steroids.

Conclusion: Gamma Knife radiosurgery is an effective and safe treatment for patients with acoustic neuroma.

Keywords: Acoustic neuroma, Gamma Knife, stereotactic radiosurgey

\section{Introduction}

Acoustic neuroma is a benign tumor that arises from the schwann cells of the vestibular branch of the $8^{\text {th }}$ cranial nerve (1-3). Although it is histopathologically benign, it can present with severe clinical symptoms and signs when the tumor compresses the adjacent brainstem and other cranial nerves. Patient's clinical course, presence of comorbid diseases, and size of lesion are important factors in deciding on the treatment for acoustic neuroma. Treatment options are no treatment with imaging follow-up, microsurgery, and stereotactic radiosurgery (4). Microsurgery is the most effective and standard treatment method in patients with acoustic neuroma. However, serious morbidities such as hearing loss, permanent facial paralysis, cerebrospinal fluid fistula, and meningitis can be seen after the surgery.

Stereotactic radiosurgery is a method in which a high-dose radiation is applied on a specific target in the brain at a single session. Gamma Knife, which was first used in 1968, is a stereotactic radiosurgery technique that includes 192 or 201 Cobalt-60 sources (5). Gamma Knife provides an effective and safe treatment, particularly in single lesions with a maximum diameter of 3-3.5 cm. Although the standard treatment method is considered to be microsurgery in patients with acoustic neuroma, Gamma Knife has become an important treatment option, especially for small and middle-sized lesions owing to its advantages, including its association with low morbidity, applicability as an outpatient treatment, and short recovery time (6). In this study, patients treated for acoustic neuroma with Gamma Knife in our clinic were retrospectively evaluated.

\section{Methods}

Patients' characteristics: Patients with acoustic neuroma undergoing treatment in the Gamma Knife Unit at Bezmialem Vakif University between August 2014 and May 2015 were included in the study. The age, sex, complaints, and clinical findings of the patients, radiosurgical treatment data were retrospectively examined. 
Hearing and facial nerve function: Hearing functions of the patients were evaluated using the Gardner-Robertson Hearing classification system, and facial nerve functions were evaluated through the House-Breckmann Facial Nerve Grading system (7).

Radiological evaluation: Tumor volumes were measured using GammaPlan software on magnetic resonance (MR) images taken before and after gamma knife. Using contrastenhanced T1-weighted MR images on GammaPlan, the contours of lesions were drawn and their volumes were determined.

Stereotactic radiosurgery technique: Gamma knife radiosurgery was performed in patients using Leksell Gamma Knife Model C (Elekta, Stocholm, Sweden). The treatment is initiated by placing a Leksell stereotactic head-frame on the head of the patient under sedation and analgesia application. Treatment plan is performed using contrast-enhanced axial and coronal T1-weighted and axial T2-weighted CISS MR images with $1 \mathrm{~cm}$ thickness.

Patient follow-up: After Gamma Knife, patients are clinically and radiologically followed up at 3, 6, 12, 18, and 24 months. Hearing test is also performed at each clinical assessment.

\section{Results}

Patient characteristics: Between August 2014 and March 2015, 18 patients (11 males and 7 females) diagnosed with acoustic neuroma were treated with Gamma Knife in our unit. The median age was 56 years (38-72 years). At admission, the complaints were headache in seven patients $(38 \%)$, hearing loss in five patients $(27 \%)$, dizziness in five patients (27\%), facial numbness in two patients $(11 \%)$, and unsteady gait in one patient (5\%). Gardner-Robertson hearing and House-Breckman facial paralysis scores of patients before gamma knife are presented in Tables 1 and 2, respectively. Moreover, patients' demographic information, treatment data, and results are shown in Table 3.

Radiological evaluation: The lesion was on the left side in 14 patients $(78 \%)$ and on the right side in 4 patients (22\%). The tumor extended into the internal acoustic canal in 15 patients $(83 \%)$, and brainstem compression was observed in 4 patients $(22 \%)$. The median tumor volume was $1.94 \mathrm{~cm}^{3}$ $\left(0.25-14 \mathrm{~cm}^{3}\right)$.

Gamma knife treatment: The median radiosurgical prescription dose was $12.5 \mathrm{~Gy}(12-13 \mathrm{~Gy})$. The treatment dose was administered at $12 \mathrm{~Gy}$ in seven patients, $12.5 \mathrm{~Gy}$ in five, and 13 Gy in six. In all patients, 50\% isodose line was used (Figure 1). Each patient was administered with $16 \mathrm{mg}$ dexamethasone after Gamma Knife treatment, if there was no contraindication.

Tumor control: The median follow-up duration was 4 months (1-8 months). The tumor size increased in 1 patient
$(5 \%)$, decreased in 3 patients (17\%), and remained stable in 14 patients $(78 \%)$.

Gamma knife-related complications: Left hemiparesthesia developed only in one of 18 patients (5\%). Patient's symptom was resolved after one-month use of steroid. Hearing in all patients was preserved during their follow-ups and no newly developed facial paresis or paralysis was observed.

\section{Discussion}

In this study, preliminary results of patients with acoustic neuroma, who were treated in the Gamma Knife Unit at Bezmialem Vakif University, were presented. It was observed that the treatment was effective and complication rate was acceptable in the short-term assessment of patients with acoustic neuroma treated for 8 months in our unit. The efficiency of Gamma Knife in acoustic neuromas generally occurs after 1 year and the control rate of tumor after 2 years is approximately $85 \%$. Stable and reduced tumor volume indicates that Gamma Knife is an effective treatment.

Gamma knife radiosurgery is an effective and safe method for the treatment of small and mid-sized acoustic neuromas. Studies have shown that Gamma Knife controls the tumor growth and maintains neurological function (8, 9). A study having level I evidence revealed that Gamma Knife was superior to microsurgery in terms of functional outcome and quality of life $(10,11)$. It was reported that the rate of facial paresis, which particularly impairs the

\begin{tabular}{|c|c|c|c|}
\hline & PTA*(dB) & $\begin{array}{l}\text { Number of } \\
\text { SD** (\%) }\end{array}$ & patients \\
\hline Stage 1: Good & $0-30$ & $70-100$ & 2 \\
\hline Stage 2: Functional & $31-50$ & $50-69$ & 3 \\
\hline Stage 3: Non-functional & $51-90$ & $5-49$ & 6 \\
\hline Stage 4: Poor & $90-100$ & $1-4$ & 2 \\
\hline Stage 5: Deaf & 0 & 0 & 5 \\
\hline
\end{tabular}

Table 2. House-Breckmann facial nerve grading in patients treated with Gamma Knife for acoustic neuroma

\begin{tabular}{|l|c|c|}
$\begin{array}{l}\text { House- } \\
\text { Breckman stage }\end{array}$ & Definition & $\begin{array}{c}\text { Number of } \\
\text { patients }\end{array}$ \\
\hline I & Normal & 9 \\
II & Mild & 2 \\
III & Moderate & 2 \\
IV & Moderate-severe & 1 \\
V & Severe & 0 \\
VI & Total palsy & 0 \\
\hline
\end{tabular}


Table 3. Demographic and treatment data of patients with acoustic neuroma treated with gamma knife

\begin{tabular}{|c|c|c|c|c|c|c|c|}
\hline $\begin{array}{l}\text { Patient } \\
\text { no }\end{array}$ & Age & Sex & Complaint & $\begin{array}{c}\text { Tumor volume } \\
\left(\mathrm{cm}^{3}\right)\end{array}$ & $\begin{array}{c}\text { Treatment } \\
\text { dose (Gy) }\end{array}$ & $\begin{array}{c}\text { Duration of } \\
\text { follow-up (month) }\end{array}$ & $\begin{array}{c}\text { Response to } \\
\text { treatment }\end{array}$ \\
\hline 1 & 38 & Male & Hearing loss & 6.52 & 13 & 6 & Stable \\
\hline 2 & 57 & Male & Headache & 10.9 & 12 & 3 & Stable \\
\hline 3 & 38 & Female & Headache & 3.67 & 12 & 3 & Stable \\
\hline 4 & 51 & Male & Dizziness & 1.76 & 12 & 4 & Stable \\
\hline 5 & 43 & Female & Tinnitus & 1.71 & 12.5 & 4 & Stable \\
\hline 6 & 64 & Male & Hearing loss and tinnitus & 3.56 & 12.5 & 4 & Stable \\
\hline 7 & 53 & Female & Hearing loss & 0.4 & 13 & 8 & Decreased \\
\hline 8 & 53 & Male & Headache & 1.68 & 13 & 6 & Stable \\
\hline 9 & 69 & Female & Hearing loss & 1.13 & 12 & 4 & Stable \\
\hline 10 & 47 & Male & Tinnitus & 2.12 & 13 & 4 & Stable \\
\hline 11 & 62 & Male & Headache & 0.25 & 13 & 8 & Stable \\
\hline 12 & 61 & Male & Hearing loss & 2.51 & 12.5 & 4 & Stable \\
\hline 13 & 66 & Male & Headache & 8.59 & 12.5 & 8 & Decreased \\
\hline 14 & 72 & Female & Hearing loss & 14 & 12 & 8 & Stable \\
\hline 15 & 63 & Female & Tinnitus & 1.75 & 12 & 7 & Increased \\
\hline 16 & 67 & Male & Dizziness & 0.25 & 13 & 8 & Decreased \\
\hline 17 & 62 & Male & Dizziness & 5.27 & 12 & 4 & Stable \\
\hline 18 & 47 & Female & Dizziness & 2.37 & 12.5 & 4 & Stable \\
\hline
\end{tabular}

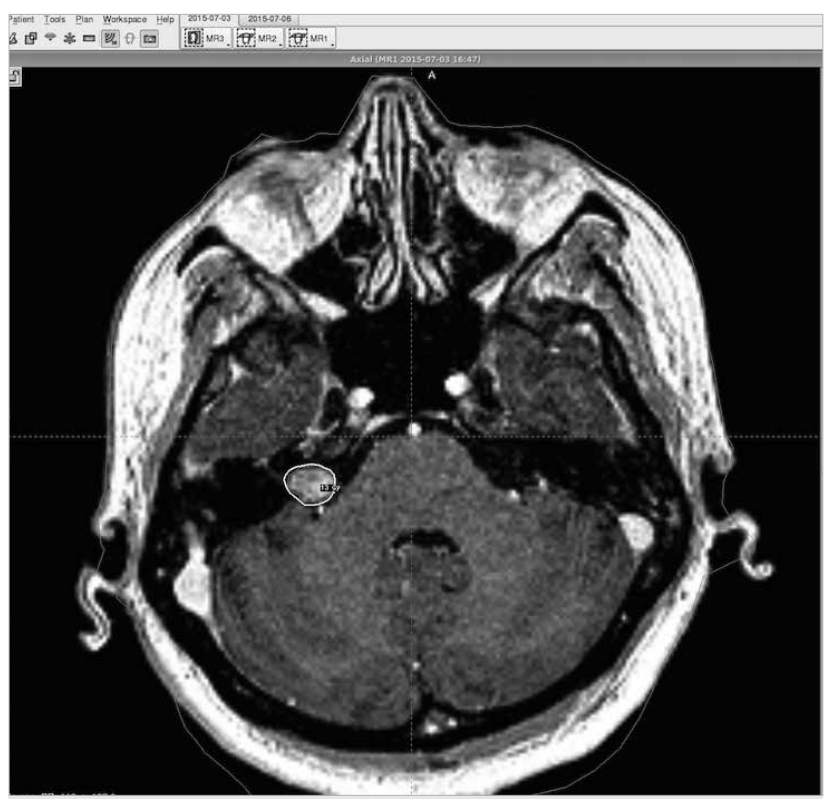

Figure 1. Treatment plan of patients with right acoustic neuroma on GammaPlan. The dose of 13 Gy was defined on $50 \%$ isodose curve.

quality of life of patients, was $2 \%-3 \%$, and the rate of hearing loss was $50 \%$ after microsurgery. In addition, cerebrospinal fluid fistula, meningitis, and other cranial nerve damages are complications that may develop after microsurgery (12). After Gamma Knife, the rate of facial paralysis is approximately $1 \%-2 \%$ and that of hearing loss is $20 \%-30 \%$. The probability of hearing protection is higher in Gamma Knife than in surgery. Especially in small tumors in which hearing is still good, Gamma Knife treatment is a highly effective treatment method $(13,14)$. Gamma knife, which is comparable to microsurgery, is a safe treatment option in small to mid-sized lesions without a mass effect.

Different treatment doses have been administered over years and their efficiencies and reliabilities have been examined. It has been reported that decreased radiation dose does not completely protect hearing, but provides better hearing results than higher doses. Hearing is better protected through treatment with a dose of $13 \mathrm{~Gy}$ (15). The mean dose was $14.2 \mathrm{~Gy}$ in the studies between the years of 1998 and 2007 (12, 13). In the studies between 2007 and 2011, prescription dose was lower than that in previous studies and a dose of 12-13 Gy was recommended. Sun et al. (16) applied Gamma Knife treatment at the median peripheral treatment dose of $13.6 \mathrm{~Gy}$ on $45 \%$ isodose curve and Wangerid et al. (17) at the median dose of 12.3 on $50 \%$ isodose curve. These data are consistent with those of our study.

Wangerid et al. (17), Hasegawa et al. (18), and Sun et al. (16) reported effective tumor control rates. Reduction in tumor size was observed in $72 \%, 58 \%$, and $64 \%$, respectively, and tumor size was stable in 20\%, 34\%, and 23\%, respectively. It was specified that temporary growth was seen in tumor in the 3rd-6th months, but reduction was observed during follow-ups (16). In our study, despite the short du- 
ration of follow-up, reduction in tumor size was detected in three patients. Increased lesion size was found only in one patient and no clinical finding was observed in this patient and as stated in the literature, this growth is believed to be temporary. In this study, early results of patients with acoustic neuroma were presented. Because they were our preliminary results, the durations of follow-ups were short and were therefore insufficient to present the results of the final treatment. This is a limitation of this study. Patients will be followed up for a longer period and the results will be evaluated. However, our preliminary results are consistent with those of the literature, and the treatment seems to be successful.

Gamma knife-induced hemihypoesthesia developed in only one patient, who recovered with a short-term steroid treatment in our cohort. Recently, developed facial paralysis or impaired hearing was not observed in any patient during their follow-ups. Hasegawa et al. (18) found the rates of hearing protection at the end of the $3 \mathrm{rd}$ and 5 th years to be $58 \%$ and $46 \%$, respectively, in patients receiving prescription dose of $<13 \mathrm{~Gy}$, and to be $37 \%$ and $19 \%$, respectively, in patients receiving treatment of $>13 \mathrm{~Gy}$.

In Turkey, there is no scientific data on the cost of Gamma Knife and its comparison with surgery. In general, the cost of Gamma Knife, which is performed in a day and does not require hospitalization, is lower considering the costs of operation, post-operative intensive care, and hospital stay in surgical treatment. In a study performed on patients with brain metastasis in the United States of America, it was specified that the cost of surgical resection was approximately US\$ 27,500 and the cost of gamma knife was approximately US\$ 20,200 (17).

\section{Conclusion}

The standard treatment method in patients with acoustic neuroma is tumor resection with microsurgery. Gamma knife radiosurgery helps to control small and mid-sized acoustic neuromas in an effective and safe manner. In addition to providing an effective tumor control in acoustic neuromas, it is a safe treatment option with acceptable complication rates. It is an alternative method to microsurgery in patients with small and mid-sized lesions and with comorbidities under high surgical risks.

Ethics Committee Approval: Ethics committee approval was received for this study from Bezmiâlem Vakıf University Ethics Committee (No: 71306642-050.01.04)

Informed Consent: Informed consent was not received due to the retrospective nature of this study.

Peer-review: Externally peer-reviewed.

Author Contributions: Concept - M.A.H., E.D., M.Ö.; Design M.A.H., E.D., M.Ö.; Supervision - M.A.H., S.T.; Funding - M.A.H.,
S.T., H.S.; Materials - H.S.; Data Collection and/or Processing - E.D., M.Ö.; Analysis and/or Interpretation - M.A.H., M.Ö., H.S., E.D., S.T.; Literature Review - E.D., M.Ö.; Writing - M.A.H., M.Ö., H.S., E.D., S.T.; Critical Review - S.T., M.A.H.

Conflict of Interest: No conflict of interest was declared by the authors.

Financial Disclosure: The authors declared that this study has received no financial support.

\section{References}

1. Arthurs BJ, Fairbanks RK, Demakas JJ, Lamoreaux WT, Giddings NA, Mackay AR, et al. A review of treatment modalities for vestibular schwannoma. Neurosurg rev 2011; 34: 265-77; discussion 77-9. [CrossRef]

2. Fortnum H, O'Neill C, Taylor R, Lenthall R, Nikolopoulos T, Lightfoot $\mathrm{G}$, et al. The role of magnetic resonance imaging in the identification of suspected acoustic neuroma: a systematic review of clinical and cost effectiveness and natural history. Health Technol Assess 2009; 13: iii-iv, ix-xi, 1-154.

3. Rykaczewski B, Zabek M. A meta-analysis of treatment of vestibular schwannoma using Gamma Knife radiosurgery. Contemp Oncol (Pozn) 2014; 18: 60-6. [CrossRef]

4. Patel J, Vasan R, van Loveren H, Downes K, Agazzi S. The changing face of acoustic neuroma management in the USA: analysis of the 1998 and 2008 patient surveys from the acoustic neuroma association. Br J Neurosurg 2014; 28: 20-4. [CrossRef]

5. Elaimy AL, Mackay AR, Lamoreaux WT, Demakas JJ, Fairbanks RK, Cooke BS, et al. Clinical outcomes of gamma knife radiosurgery in the salvage treatment of patients with recurrent high-grade glioma. World Neurosur 2013; 80: 872-8. [CrossRef]

6. Wang J, Xu Y, Lei T, Zeng L. Treatment decision-making for sporadic small vestibular schwannoma in a pediatric patient: A case report and literature review. Oncol lett 2015; 9: 2371-3. [CrossRef]

7. Fezeu F, Lee CC, Dodson BK, Mukherjee S, Przybylowski CJ, Awad AJ, et al. Stereotactic radiosurgery for facial nerve schwannomas: A preliminary assessment and review of the literature. $\mathrm{Br} \mathrm{J}$ Neurosurg 2015; 29: 213-8. [CrossRef]

8. Sughrue ME, Kane AJ, Kaur R, Barry JJ, Rutkowski MJ, Pitts LH, et al. A prospective study of hearing preservation in untreated vestibular schwannomas. Journal of neurosurgery. 2011; 114: 381-5. [CrossRef]

9. Sughrue ME, Yang I, Aranda D, Lobo K, Pitts LH, Cheung SW, et al. The natural history of untreated sporadic vestibular schwannomas: a comprehensive review of hearing outcomes. J Neurosurg 2010; 112: 163-7. [CrossRef]

10. Murphy ES, Barnett GH, Vogelbaum MA, Neyman G, Stevens $\mathrm{GH}$, Cohen BH, et al. Long-term outcomes of Gamma Knife radiosurgery in patients with vestibular schwannomas. J Neurosurg 2011; 114: 432-40. [CrossRef]

11. Pollock BE, Driscoll CL, Foote RL, Link MJ, Gorman DA, Bauch $\mathrm{CD}$, et al. Patient outcomes after vestibular schwannoma management: a prospective comparison of microsurgical resection and stereotactic radiosurgery. Neurosurgery 2006; 59: 77-85; discussion 77-85. [CrossRef]

12. Vachhrajani S, Fawaz C, Mathieu D, Menard C, Cusimano MD, Gentili F, et al. Complications of Gamma Knife surgery: an early report from 2 Canadian centers. J neurosurg 2008; 109 Suppl: 2-7.

13. Iwai $Y$, Yamanaka K, Kubo T, Aiba T. Gamma knife radiosurgery for intracanalicular acoustic neuromas. Journal of clinical neuroscience : official journal of the Neurosurgical Society of Australasia 2008; 159: 993-7. [CrossRef]

14. Niranjan A, Lunsford LD, Flickinger JC, Maitz A, Kondziolka D. Dose reduction improves hearing preservation rates after intracanalicular acoustic tumor radiosurgery. Neurosurgery 1999; 45: 75362; discussion 62-5. [CrossRef] 
15. Yang I, Sughrue ME, Han SJ, Fang S, Aranda D, Cheung SW, et al. Facial nerve preservation after vestibular schwannoma Gamma Knife radiosurgery. J Neurooncol 2009; 93: 41-8. [CrossRef]

16. Nakamura H, Jokura H, Takahashi K, Boku N, Akabane A, Yoshimoto T. Serial follow-up MR imaging after gamma knife radiosur- gery for vestibular schwannoma. AJNR Am J Neuroradiol 2000; 21: 1540-6.

17. Vuong DA, Rades D, van Eck AT, Horstmann GA, Busse R. Comparing the cost-effectiveness of two brain metastasis treatment modalities from a payer's perspective: stereotactic radiosurgery versus surgical resection. Clin Neurol Neurosurg 2013; 115: 276-84. [CrossRef] 